Note

\section{The Induction of Cyanide-resistant Respiration in the Absence of Respiratory Inhibitors in Hansenula anomala}

\author{
Nobuko Minagawa and Akio Yoshimoto \\ Department of Biochemistry, Niigata \\ College of Pharmacy, Niigata, \\ Niigata 950-21, Japan
}

Received March 2, 1987

Cyanide-resistant respiration has been reported in a variety of organisms, including higher plants, algae, fungi, and some bacteria. ${ }^{1,2)}$ This cyanide-resistant $\mathrm{O}_{2}$ uptake takes place on the inner mitochondrial membrane in eukaryotes, and appears to constitute a pathway alternative to the main cyanide-sensitive cytochrome pathway. Although much work has been devoted to the pathway, the exact biochemical characteristics of the cyanideresistant oxidase ("alternative oxidase") remain unknown.

The induction of cyanide-resistant respiration in the presence of cyanide or Antimycin A was observed in the ascomycetous yeast, Hansenula anomala, ${ }^{3)}$ as previously reported for other fungi. ${ }^{4,5)}$ Oxygen is required for this induction process, including de novo protein synthesis which is completely blocked by cycloheximide. ${ }^{3)}$ In this paper, we report the induction of cyanide-resistant respiration in this organism in the absence of respiratory inhibitors. Since we sometimes observed cyanide-resistant $\mathrm{O}_{2}$ uptake in freshly harvested cells and this respiration is reported to increase with the aging of higher plants, ${ }^{1,2)}$ this induction process may be involved in the in vivo regulation of the energy metabolism in $H$. anomala.

Yeast extract was purchased from Difco Laboratories. Hansenula anomala LKBY-1 was grown at $30^{\circ} \mathrm{C}$ in the liquid medium described previously ${ }^{6}$ ) with yeast extract $(1 \mathrm{~g} / \mathrm{l})$ as a sole source of nitrogen. The cells were harvested at early stationary phase where the cyanide-resistant respiration was induced most readily. ${ }^{3)}$ The oxygen uptake was measured polarographically with an oxygen electrode Model 5331 (Yellow Springs Instrument Co., Inc., Ohio) in a 2-ml glass chamber maintained at $30^{\circ} \mathrm{C}$. The chamber received $0.04 \mathrm{M}$ potassium phosphate buffer $(\mathrm{pH} \mathrm{6.5)}$ and $0.05 \mathrm{M}$ glucose in a final volume of $2.0 \mathrm{ml}$. The assay was started by the addition of cell suspension, followed by the addition of $1 \mathrm{~mm}$ potassium cyanide. The respiration activity resistant to $1 \mathrm{~mm}$ potassium cyanide was defined as cyanide-resistant respiration and expressed as $\mu$ mol $\mathrm{O}_{2}$ consumed/min.

Figure 1 demonstrates the effects of cell concentration on the induction of the cyanide-resistant respiration. Cyanide-resistant respiration was also induced in the absence of respiratory inhibitors, where the respiration was induced more readily at higher cell concentrations. The induced cyanide-resistant respiration activities in the absence of respiratory inhibitors were much lower than those induced by Antimycin A or cyanide (data are not shown). These resuls were partially in agreement with and somewhat different from the results reported on Candida albicans ${ }^{7)}$ where cell concentration was also critical for the induction and below the cell concentration of $5 \times 10^{8} / \mathrm{ml}$ $\left(A_{550}=12\right)$ the induction could not be observed. This induction in $H$. anomala did not occur under anaerobic conditions and was completely blocked by cycloheximide, an inhibitor of cytosolic protein synthesis, as well as the induction in the presence of respiratory inhibitors. ${ }^{3)}$ Accordingly, the induction mechanism in the absence of respiratory inhibitors is deduced to be essentially similar to that induced by those inhibitors. At present further investigation is necessary to elucidate this concentration-dependence. Possible explanations might be the excretion by the cells of certain metabolite(s) which accelerate the induction of the cyanide-resistant respiration, or effects of oxygen concentration in the medium.

Figure 2 shows the effects of phosphate buffer concentration on the induction of the cyanide-resistant respiration. As can be seen, the most induction was observed with the cell suspension in water. Phosphate inhibited the

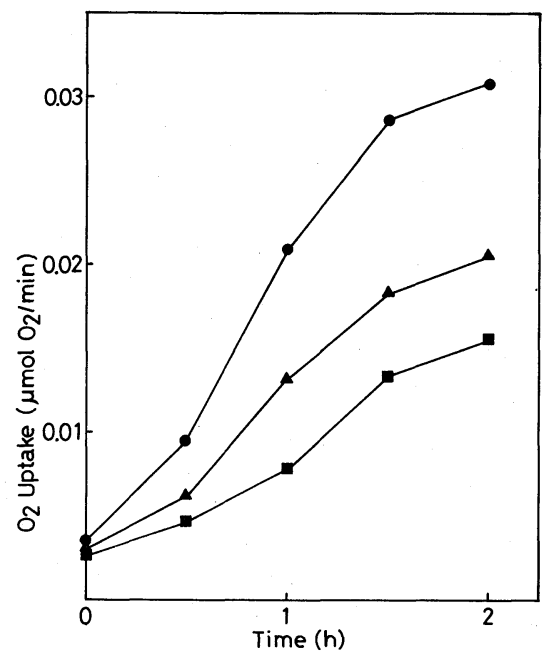

FIG. 1. Effects of Cell Concentration on the Induction of the Cyanide-resistant Respiration.

Cells suspended in $50 \mathrm{~mm}$ potassium phosphate buffer $(\mathrm{pH}$ $6.5)$ at the indicated turbidity were shaken at $30^{\circ} \mathrm{C}$ in air. Samples withdrawn at the indicated times $(5.82 \mathrm{mg}$ wet weight or $1.24 \mathrm{mg}$ dry weight) were assayed. Absorbance at $600 \mathrm{~nm}$ of the suspension was adjusted to, 100 ; 25 ;, 5 . 


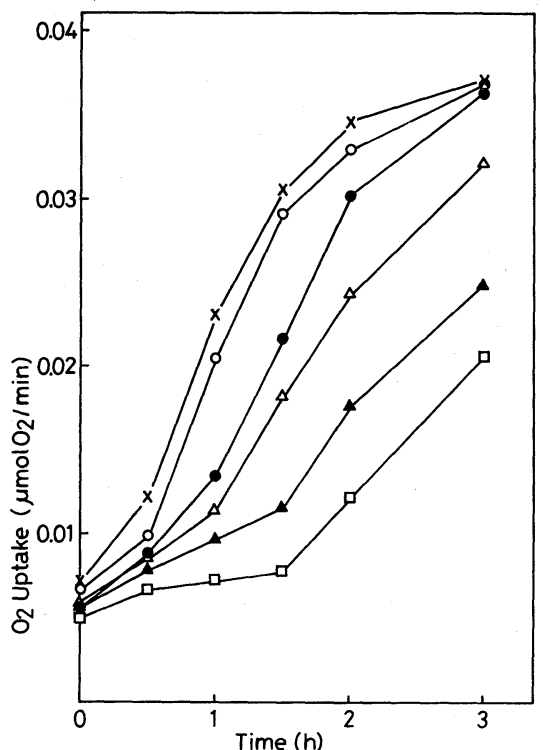

FIG. 2. Effects of Phosphate Buffer (pH 6.5) Concentration on the Induction of the Cyanide-resistant Respiration.

The cells suspended in the indicated concentration of potassium phosphate buffer $\left(\mathrm{pH} \mathrm{6.5)}\right.$ were shaken at $30^{\circ} \mathrm{C}$ in air. Samples $(5.82 \mathrm{mg}$ wet weight) withdrawn at the indicated times were assayed. $\times$, no addition; $\bigcirc, 5 \mathrm{~mm}$; ○, $50 \mathrm{~mm}, \triangle, 150 \mathrm{~mm} ; \Delta, 300 \mathrm{~mm} ; \square, 500 \mathrm{~mm}$.

induction, and the cyanide-resistant respiration was induced biphasically at high concentrations of phosphate.

Figure 3 demonstrates the effects of glucose on the induction. More than $50 \mathrm{~mm}$ glucose almost completely repressed the induction of the cyanide-resistant respiration. With $20 \mathrm{~mm}$ glucose, slight induction occurred after $2 \mathrm{hr}$, where glucose seemed to be almost all metabolized. Five millimolar glucose had little repressive effect under these experimental conditions. Effects of other compounds used as carbon sources in this organism ${ }^{8)}$ were examined (Fig. 4). Fructose and ethanol had similar effects to those of glucose. Sucrose was repressive after $1 \mathrm{hr}$, probably because of the delay required for hydrolysis. Galactose and 6-deoxy glucose, which could not be used as carbon sources, had no effect on the induction. Sole or combined addition of malate and succinate also had no effect. Nitrate or yeast extract used as nitrogen sources also had no effect on the induction. Further investigation is in progress to elucidate these repressive effects by glucose on the induction mechanism.

\section{REFERENCES}

1) H. Lambers, Physiol. Plant., 55, 478 (1982).

2) J. N. Siedow and D. A Berthold, Physiol. Plant., 66,

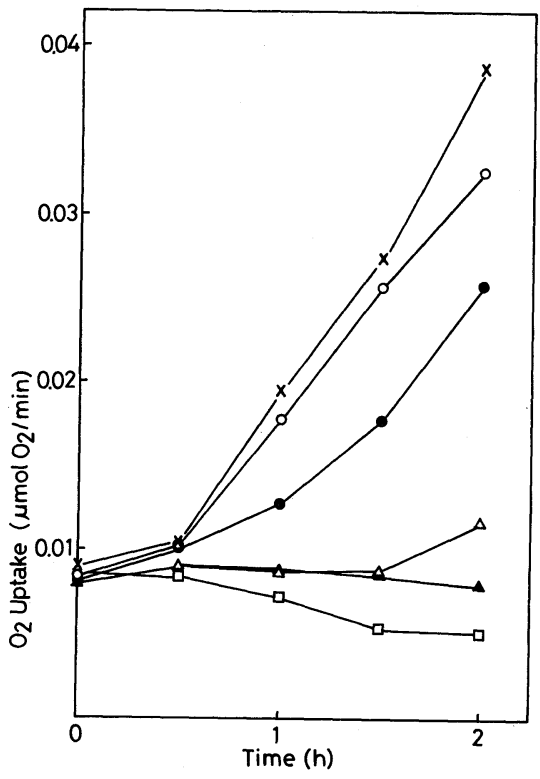

FIG. 3. Effects of Glucose Concentration on the Induction of the Cyanide-resistant Respiration.

Cells suspended in $10 \mathrm{~mm}$ potassium phosphate buffer $(\mathrm{pH}$ 6.5) containing the indicated concentration of glucose were shaken at $30^{\circ} \mathrm{C}$ in air. Samples (5.82 mg wet weight) withdrawn at the indicated times were assayed. $\times$, no addition; $\bigcirc, 5 \mathrm{~mm} ; \bigcirc, 10 \mathrm{~mm}, \triangle, 20 \mathrm{~mm} ; \boldsymbol{\Delta}, 50 \mathrm{~mm} ; \square$, $100 \mathrm{~mm}$.

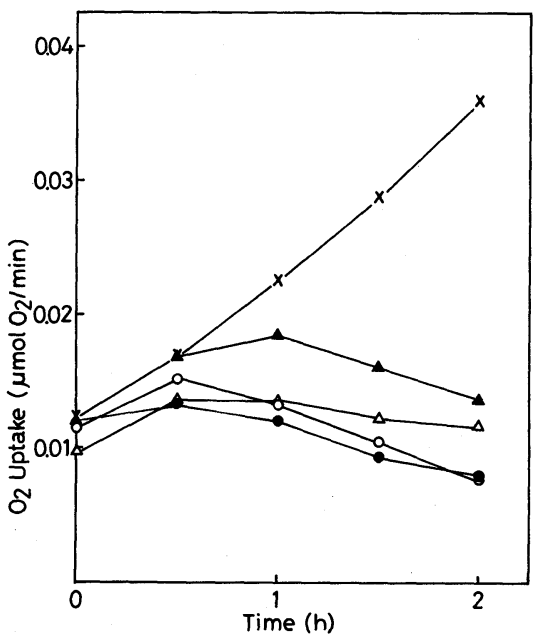

FIG. 4. Effects of the Compounds Used as Carbon Sources on the Induction of the Cyanide-resistant Respiration.

The cell suspension was treated similarly to Fig. 3 except that the compounds were added at the indicated concentration. $\times$, no addition; $\bigcirc, 50 \mathrm{~mm}$ glucose; $\bigcirc, 50 \mathrm{~mm}$ fructose; $\mathbf{\Delta}, 50 \mathrm{~mm}$ sucrose; $\triangle, 100 \mathrm{~mm}$ ethanol. 
569 (1986).

3) N. Minagawa and A. Yoshimoto, J. Biochem., 101, 1141 (1987).

4) D. L. Edwards, E. Resenberg and P. A. Maroney, $J$. Biol. Chem., 249, 3551 (1974).

5) M.-F. Henry, M. C. Hamaide-Deplus and E. J. Nyns, Antonie van Leeuwenhoek, 40, 79 (1974).
6) N. Minagawa and A. Yoshimoto, Agric. Biol. Chem., 47, 125 (1983).

7) S. Aoki and S. Ito-Kuwa, Microbiol. Immunol., 28, 393 (1984).

8) F. Pichinoty and G. Metenier, Ann. Inst. Pasteur, 112, 701 (1967). 